\title{
Comparison between Adsorption of Copper Ions by Kaolinite and Kaolinite Composite
}

\author{
Diab, M. A. ${ }^{1}$; M. Sh. Zoromba ${ }^{2}$; M.A Hussien ${ }^{2}$ and M. Sherif ${ }^{2}$ \\ ${ }^{1}$ Chemistry Department, Faculty of science, Damietta University, Egypt. \\ ${ }^{2}$ Chemistry Department, Faculty of Science, Port Said University, Egypt.
}

\section{Received: $25 / 12 / 2015$}

\begin{abstract}
In this study, removal of toxic metal $\mathrm{Cu}(\Pi)$ from contaminated water has been investigated with the aim of detoxifying industrial effluents before their safe disposal onto land or into the river. Comparison between the two lowcost adsorbents, kaolinite and poly aniline co-anthranilic acid/kaolinite were used to remove $\mathrm{Cu}$ ( $\Pi$ ) ion from synthesized waste water. Characterization study show that the composite thermally is more stable than the pure kaolinite. The effects of adsorbent amount, $\mathrm{pH}$ and contact time on adsorption efficiency were investigated. Generally, the result showed an increase in removal efficiency with increase in contact time and increase of $\mathrm{pH}$ and adsorbent dose with the both adsorbent. The modified kaolinite with PANAA is more effective than the pure kaolinite in removal of the copper ions from its solutions.
\end{abstract}

Keywords: Adsorption, $\mathrm{Cu}$ (II), industrial waste water, PANAA/kaolinite composite.

\section{INTRODUCTION}

The problem of removing pollutants from water is an important process and is becoming more important with the increasing of industrial activities. In order to solve heavy metal pollution in ecosystem, it is important to bring applicable solutions to the subject. It is possible to clean polluted environment only with long study requiring expensive and complex plants. Therefore, it is important to take effective precautions to prevent water, soils and air pollutions. There are several methods to treat the metal contaminated effluent such as precipitation, ion exchange and adsorption, etc., but the selection of the wastewater treatment methods is based on the concentration of waste and the cost of treatment. Adsorption is one of the more popular methods for the removal of heavy metals from the wastewater. In the purification process, low cost purificant-adsorbent systems are preferred. For this reason, industrial wastes and metallurgical by-products are used and also natural substances like zeolites particularly clays (Arthur and Gino, 1993; Brian and Garrison, 1998; Volzone and Tavani, 1996; Gonz!ales Pradas et al., 1994; Jinho Jung et al., 1998; Soon-Yong and Jung-Min, 1998; Baumgarten and Kirchhausen, 1997; Shukla, 2000; Rajendra et al., 1997; Backes et al., 1995). In our study, it is aimed to compare between the effect of removal of some heavy metals such as $\mathrm{Cu}$ (II) from aqueous solution by adsorption on natural kaolinite and poly aniline-co-anthranilic acid/kaolinite composite to investigate the physicochemical parameters involved during this adsorption.

\section{Materials:}

\section{MATERIALS AND METHODS}

Aniline and anthranilic acid (Aldrich), potassium dichromate (Merck), ammonia solution and hydrochloric acid (ADWIC), Kaolinite (Morgan Chemical Industry) (kaolin colloid powder, lead $(\mathrm{Pb})=$ approx. $0.001 \%$, Loss on ignition $=$ approx. $15 \%$. Kaolinte batch number 1097/6: maximum limits of impurities. All chemicals were used as received without any further purification.

\begin{abstract}
Analytical techniques
The infrared spectroscopy of both modified and unmodified samples were obtained using a Fourier transform infrared (FT-IR) RX 1, USA. The crystallinity of the modified and unmodified samples was determined by powder X-ray diffraction (model X" Pert Pro) with filtered $\mathrm{Cu} \mathrm{K} \alpha$ radiation operated at 40 $\mathrm{kV}$ and $40 \mathrm{~mA}$. The XRD pattern was recorded from $1.5^{\circ}$ to $50^{\circ}$ of $2 \theta$ with a scanning speed of $0.02^{\circ}$ of $2 \theta$ per second. Solid morphology and average crystal size were determined by scanning electron microscopy (SEM) (JEOL JXA-840 Electron Probe Micro analyzer -JAPAN). The thermal characteristic was studied from TGA, Q50, TA Instruments, USA. Experiment was carried out under $\mathrm{N} 2$ atmosphere from $30^{\circ} \mathrm{C}$ to $800^{\circ} \mathrm{C}$ at a heating rate of $20^{\circ} \mathrm{C} / \mathrm{min}$.
\end{abstract}

\section{Synthesis of polymer composite}

The poly (aniline co-anthranilic acid) kaolinite clay composite was synthesized by the in situ chemical oxidative polymerization of aniline and anthranilic acid in presence of different percentages of kaolinite. At first, aniline and o-anthranilic acid monomers $(5: 1$ in mass ratio, typically $9.12 \mathrm{ml}, 100 \mathrm{mmol}$ aniline: $2.74 \mathrm{~g}$, $20 \mathrm{mmol}$ o-anthranilic acid) were dissolved in $2 \mathrm{M} \mathrm{HCl}$. After that, the calculated amounts of kaolinite were dispersed in 10-20 $\mathrm{ml}$ acetone, respectively, under magnetic stirrer at 750-800 rpm. Then, the dispersed system was gradually added to the reactor with stirring at $0-5^{\circ} \mathrm{C}$. At the same time, potassium dichromate (initiator) which was separately dissolved in distilled water $(100 \mathrm{ml} 1 \mathrm{M} \mathrm{K} 2 \mathrm{Cr} 2 \mathrm{O} 7)$ was slowly added into the reactor. Then, the reaction was kept for $24 \mathrm{~h}$ at $0^{\circ} \mathrm{C}$. Ammonia solution ( $15 \mathrm{ml}$ of $33 \% \mathrm{NH}_{4} \mathrm{OH}$ diluted by 30 $\mathrm{ml}$ distilled water) was added drop wisely until a dark green precipitate was formed which was collected by filtration using a Büchner funnel. The collected precipitates were washed several times with deionized water, washed by ethanol to remove monomer, oligomer and excess oxidant until the filtrate became almost colorless and oven dried at $60^{\circ} \mathrm{C}$ for $24 \mathrm{hr}$. The dark green dried powder affords (PANAA)/kaolinite clay composites. 
RESULTS AND DISCUSSION

Fourier transforms infrared spectroscopy (FT-IR Spectra)

The FT-IR spectra of the kaolinite and PANAA/kaolinite composites are shown in Figures: (1 and 2).The spectra of PANAA/kaolinite composites have two major absorptions at $1575-1589 \mathrm{~cm}^{-1}$ and $1501-1514 \mathrm{~cm}^{-1}$ due to the $\mathrm{C}=\mathrm{C}$ vibrations of benzenoid and quinoid units, respectively (Shackelette et al., 1988). The strong broad peak at $3330-3385 \mathrm{~cm}^{-1}$ may be due to the stretching vibration of $\mathrm{N}-\mathrm{H}$ of secondary amines or $\mathrm{O}-\mathrm{H}$ bond as was reported (Challier and
Slade, 1994). The FT-IR spectrum of kaolinite is dominated by the band in Figures (2) centered on 1032$1028 \mathrm{~cm}^{-1}$ due to the asymmetric stretching vibration of $\mathrm{Si}-\mathrm{O}$ bond. The weak absorption bands between 3670 and $3745 \mathrm{~cm}^{-1}$ are attributed to the $\mathrm{OH}$ stretching mode. The low intensities of these bonds are suggestive of the low amount of (Al-OH, Mg-OH-Al) content in kaolinite (Bhadra and Khastgir, 2007) But the stretching modes of $\mathrm{C}=\mathrm{N}, \mathrm{C}=\mathrm{C}$, and $\mathrm{C}-\mathrm{N}$ are shifted to the lower wave numbers because of the incorporation of kaolinite composite.
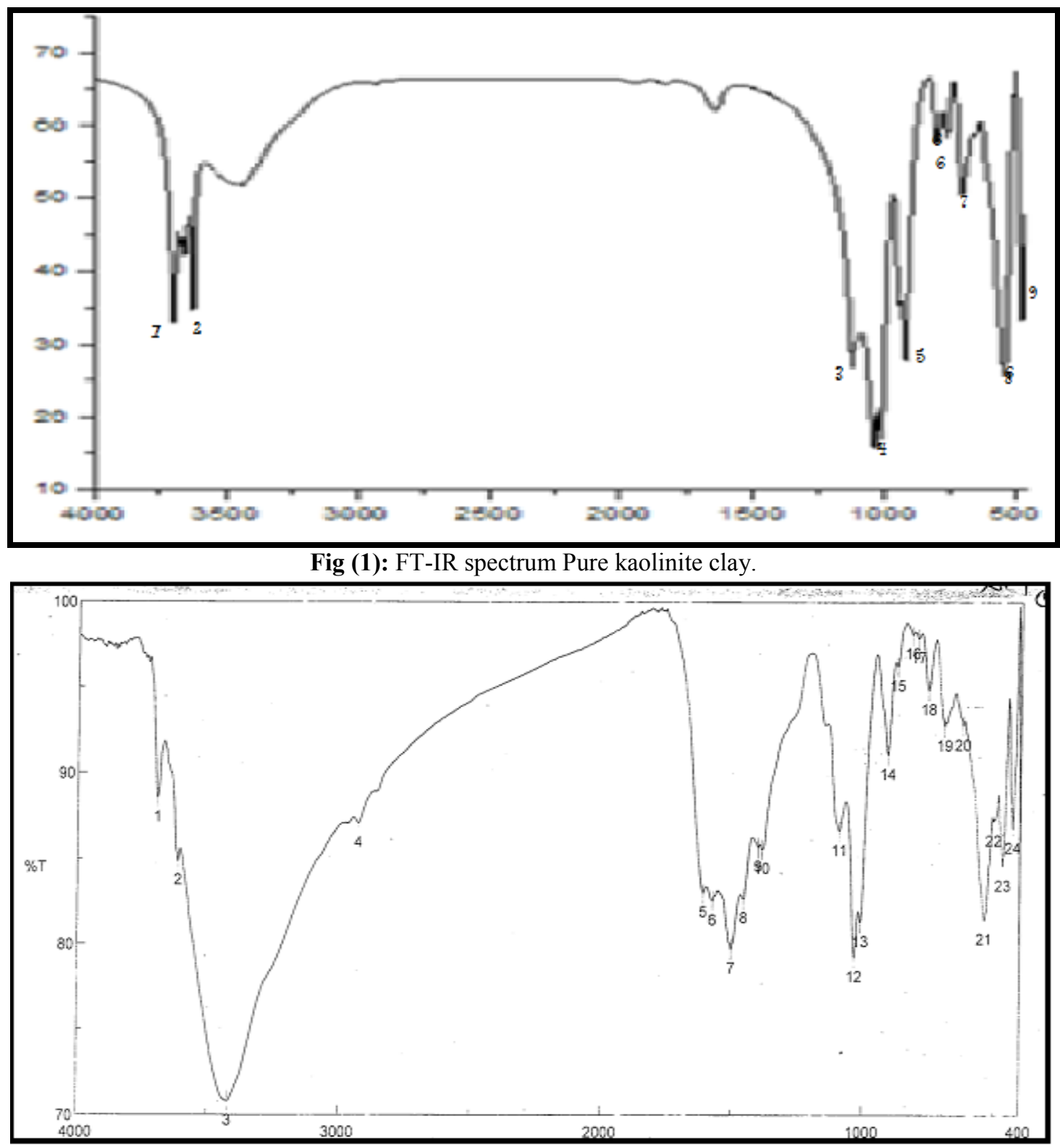

Fig. (2): FT-IR spectrum of PANAA/kaolinite composites

\section{Thermogravimetric Analysis (TGA)}

Thermal stability of PANAA/kaolinite clay composite shad been analyzed and compared with that of pure kaolinite under non-oxidative (inert gases) conditions. The weight loss patterns are shown in Figures (3 and 4) and the thermal degradation data of kaolinite and PANAA/kaolinite composite are listed in Table (1). The thermo grams of the samples taken between the room temperature and $1000^{\circ} \mathrm{C}$ were measured. The maximum char yield at $600^{\circ} \mathrm{C}$ was obtained for pure kaolinite and composite 54 and 68 respectively. The TGA data are summarized in Table (1). Results showed that the incorporation of kaolinite composite has better thermal stability than the pure kaolinite with no significant unwanted effect on the thermal degradation. 
Table (1): Thermal degradation data of the kaolinite and PANAA/kaolinite composites.

\begin{tabular}{|c|c|c|c|}
\hline Polymer code & ${ }^{\mathrm{a}} \mathbf{T}_{15}$ & $\underset{{ }^{b} \mathbf{W}_{500}}{\text { Char yield at }} 500^{\circ} \mathrm{C}$ & $\underset{{ }^{\mathrm{c}} \mathbf{W}_{600}}{\text { Char yield at } 600^{\circ} \mathrm{C}}$ \\
\hline Pure kaolinite & 374 & 61 & 54 \\
\hline KC composite & 487 & 73 & 68 \\
\hline
\end{tabular}

\footnotetext{
${ }^{\mathrm{a}} \mathrm{T}_{15}$ : Temperature of $15 \%$ weight loss.

${ }^{\mathrm{b}} \mathrm{W}_{500}$ : Char yield $\%$ at $500^{\circ} \mathrm{C}$, determined from TGA curve.

${ }^{\mathrm{c}} \mathrm{W}_{600}$ : Char yield $\%$ at $600^{\circ} \mathrm{C}$, determined from TGA curve.
}

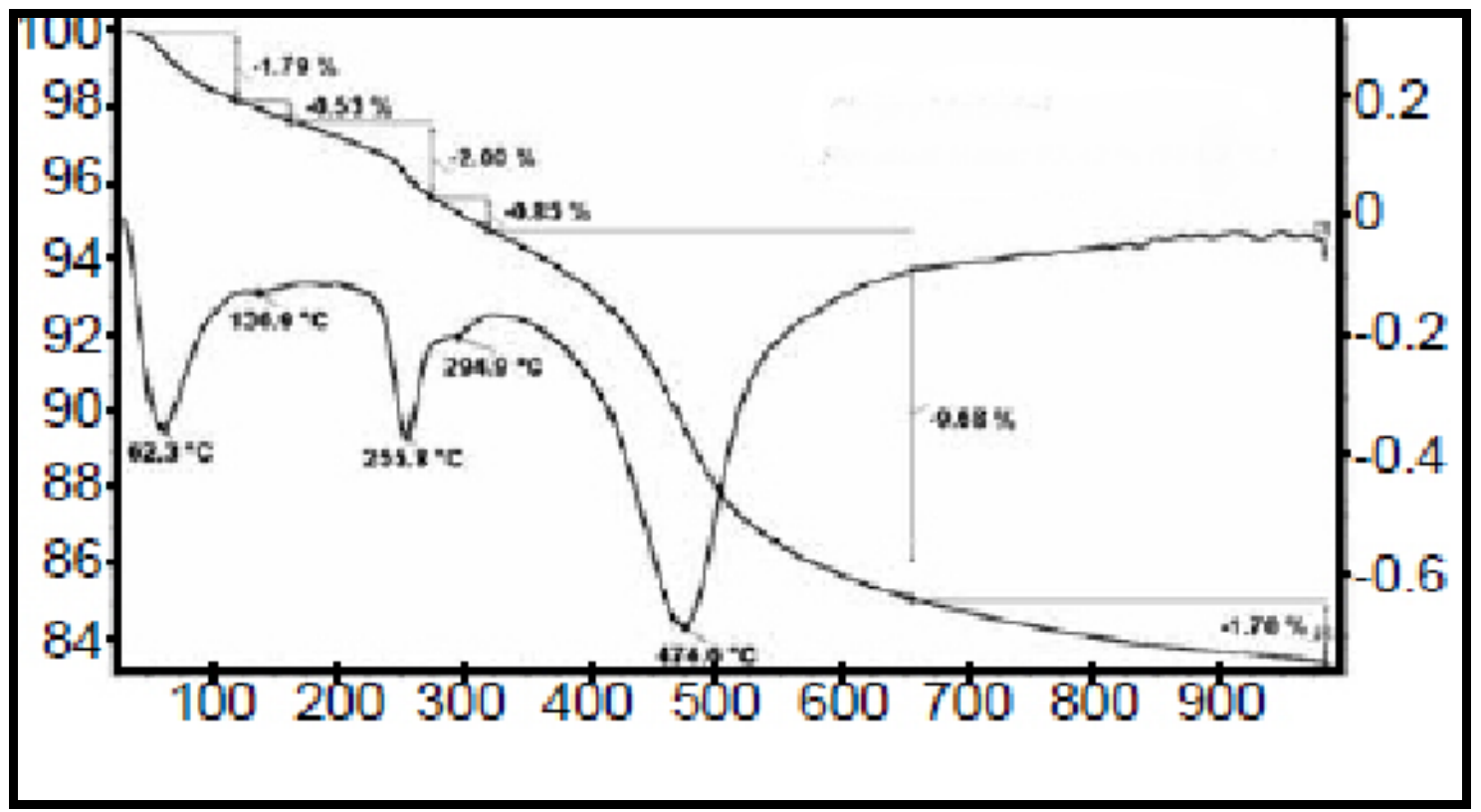

Fig. (3): TGA and DTA curves of kaolinite composite

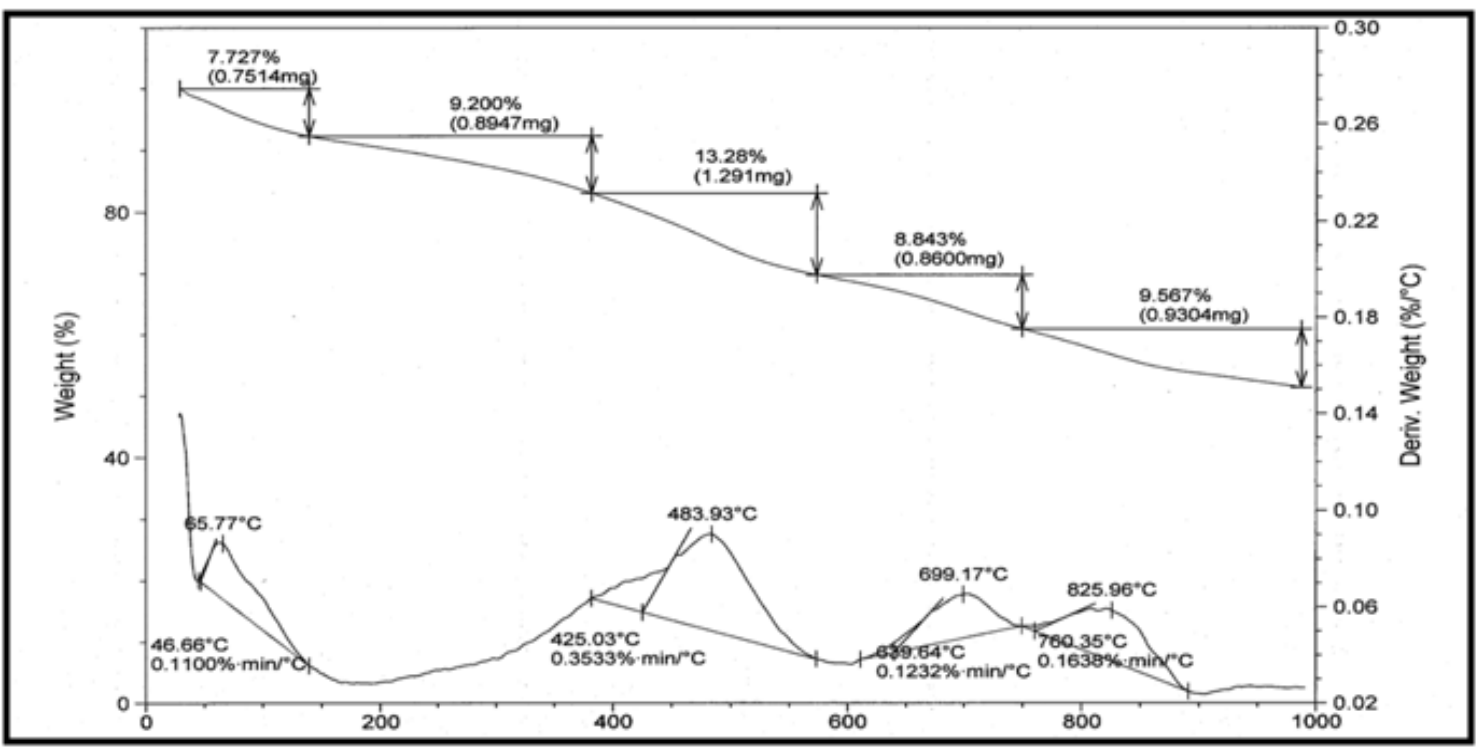

Fig. (4): TGA and DTA curves of PANAA/kaolinite composite 


\section{X-Ray Diffraction}

The X-ray powder diffraction patterns for kaolinite and PANAA/kaolinite composite shown in Figures (5 and 6) are typical of fully crystalline polymers. The sharp peaks of crystallinity corresponding to kaolinite particles were recorded at 2? angles of $24.88^{\circ}$ and $12.46^{\circ}$. Consequently, PANAA/kaolinite composite exhibited three sharp peaks at 2? angles of $44.62^{\circ}$, $24.88^{\circ}$ and $12.46^{\circ}$. XRD pattern of PANAA/kaolinite composite containing kaolinite is similar to that of pure kaolinite. The basal spacing (24.88) of pure kaolinite does not exhibit any change indicates that PANAA EB did not intercalate into the kaolinite layers. Therefore, the kaolinite clay is just coated by PANAA EB copolymer and, it did not change the crystalline structure of kaolinite clay. Similar results have been reported (Saikia and Parthasarathy, 2010; Epstein et al., 1987). Therefore, the prepared composite materials are crystalline material as shown from the $\mathrm{X}$ - ray diffraction patterns in Figures (5 and 6). All the spectra show crystalline structure without any amorphous character due to the absence of the broad peaks.

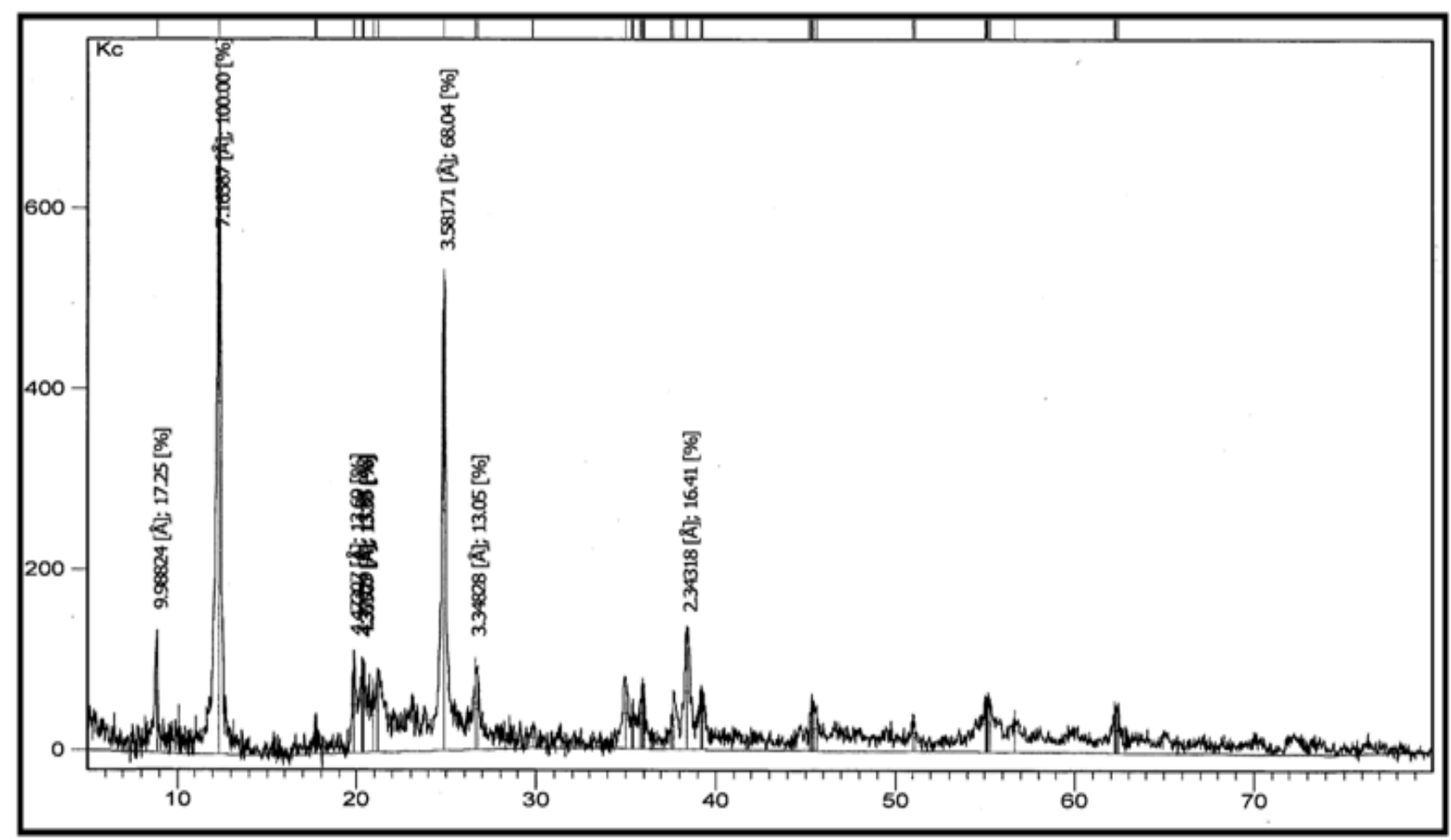

Fig. (5): XRD of kaolinite clay

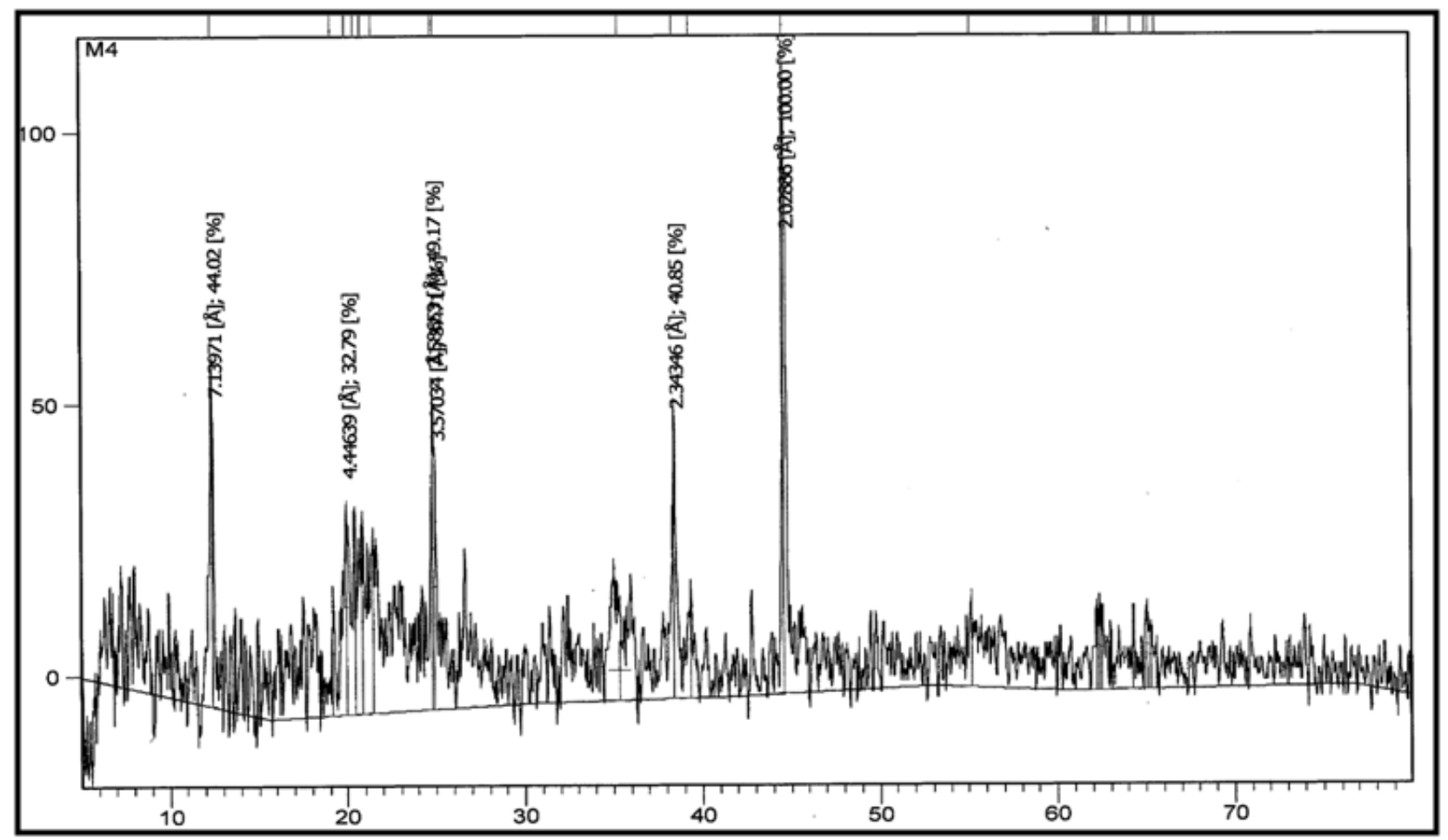

Fig. (6): XRD of Poly (aniline co-anthranilic acid/kaolinite) composite 


\section{Morphology Analysis}

Figures (7 and 8) showed the SEM images of pristine Kaolinite, the synthesized PANAA/kaolinite composites. These Figures showed pure kaolinite clay is flakes in shape. Scanning electron micrograph (SEM) revealed some interesting morphological differences between the pure kaolinite clay and PANAA emeraldine base-clay composites. The surface of pure clay was flaky texture reflecting its layered structure as shown. PANAA emeraldine base-clay composite has a flower petal-like appearance. It can be clearly seen in micrographs of all clay composites that the textures of both PANAA emeraldine base-clay are retained in the composites which are of different grain sizes. The micrographs of PANAA emeraldine base- Clay composites exhibit more ordered and dense structure (smaller sizes with high density of granules per unit area) comparing to both composite and the pure kaolinite clay (bigger sizes with less density per unit area). This also shows that polymerization of the copolymer occurs on the surface of kaolinite particles.

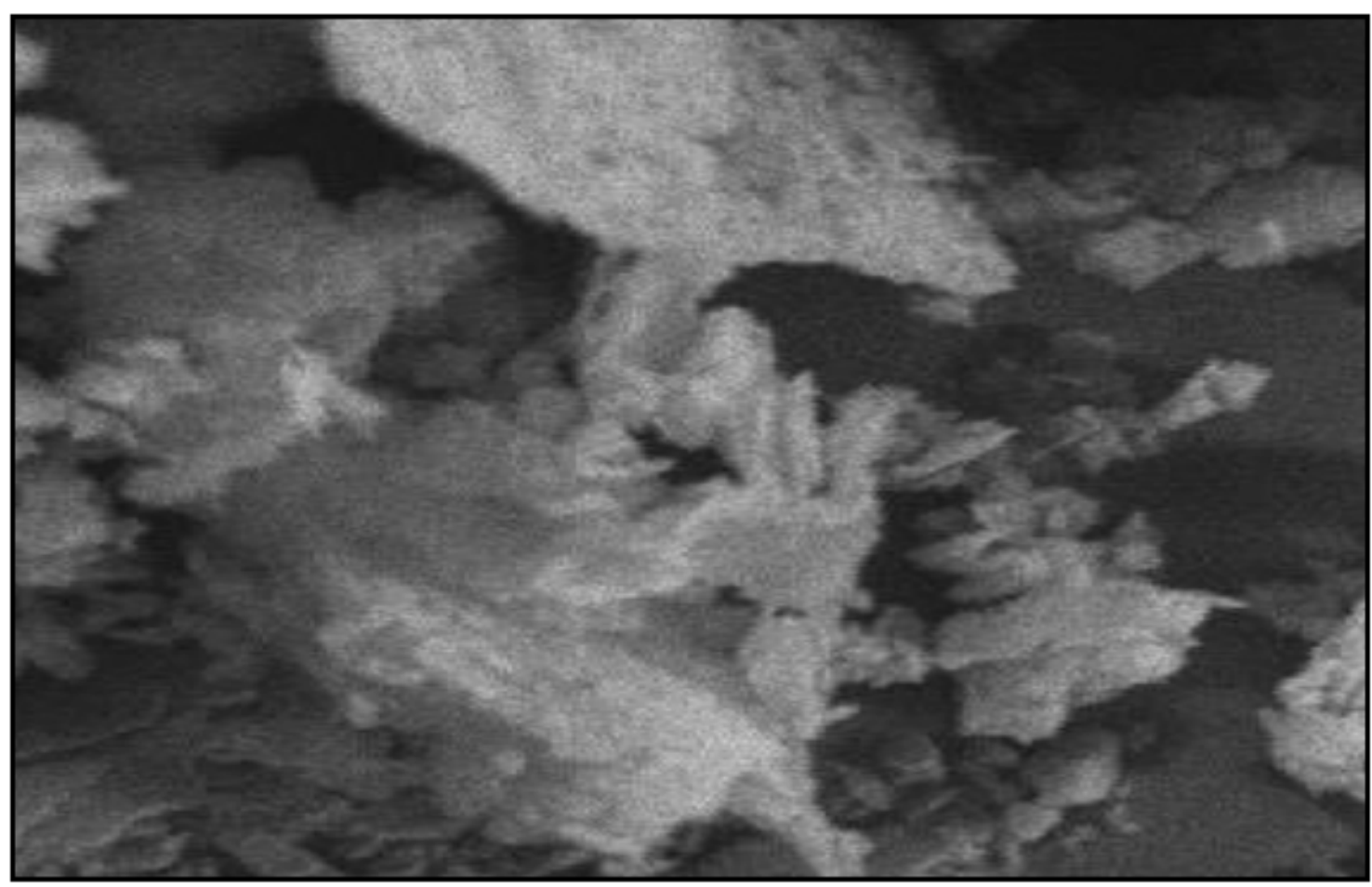

Fig. (7): SEM micrographic of Kaolinite- $\times 2500$

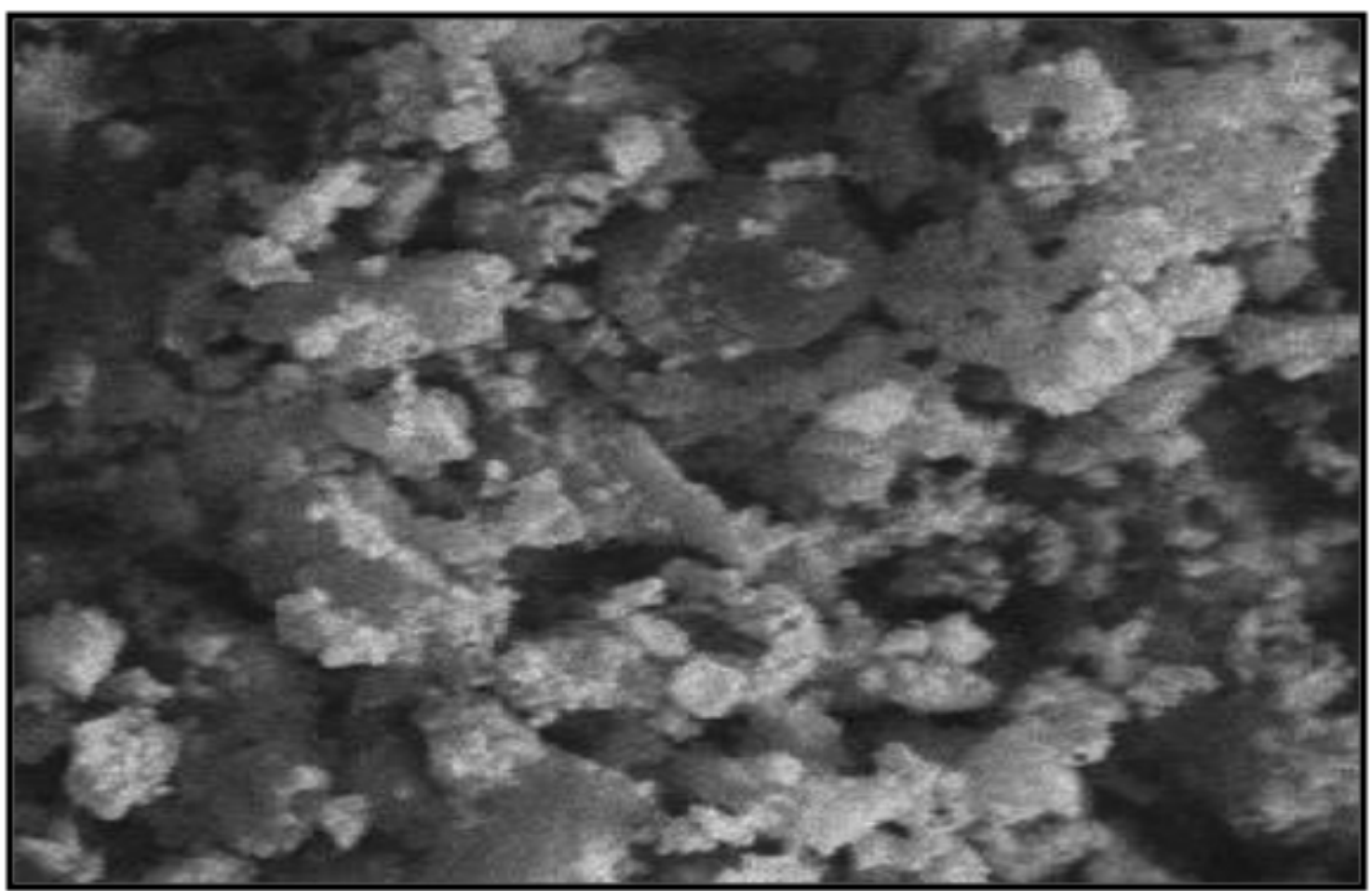

Fig. (8): SEM micrographic of PANAA/kaolinite composite $\times 2500$ 
Removal of $\mathrm{Cu}$ (II) ions using kaolinite and poly (aniline co-anthranilic acid)/kaolinite clay composite.

The effect of amount of sorbent on the removal of metal ions.

Effect of weight of pure kaolinite and its composite on the removal percentage of $\mathrm{Cu}$ (II) ions are given in Figure (9). It was found that the removal percentage reached maximum value at $0.4 \mathrm{gm} / \mathrm{L}$ for both. The removal percentage of these metal ions showed increasing trend, increased from $14.52 \%$ to
$44.2 \%$ in case of pure kaolinite and from 19.85 to $73.65 \%$ in case of composite as shown in the Figure (9). The increasing of removal percentage of Copper ions with increasing kaolinite and PANAA/kaolinite Composite amount may be due to increase in surface negative charge and decrease in the electrostatic potential near the solid surface that favors sorbentsolute interactions. This result shows that the using of modified kaolinite is more effective than the pure clay.

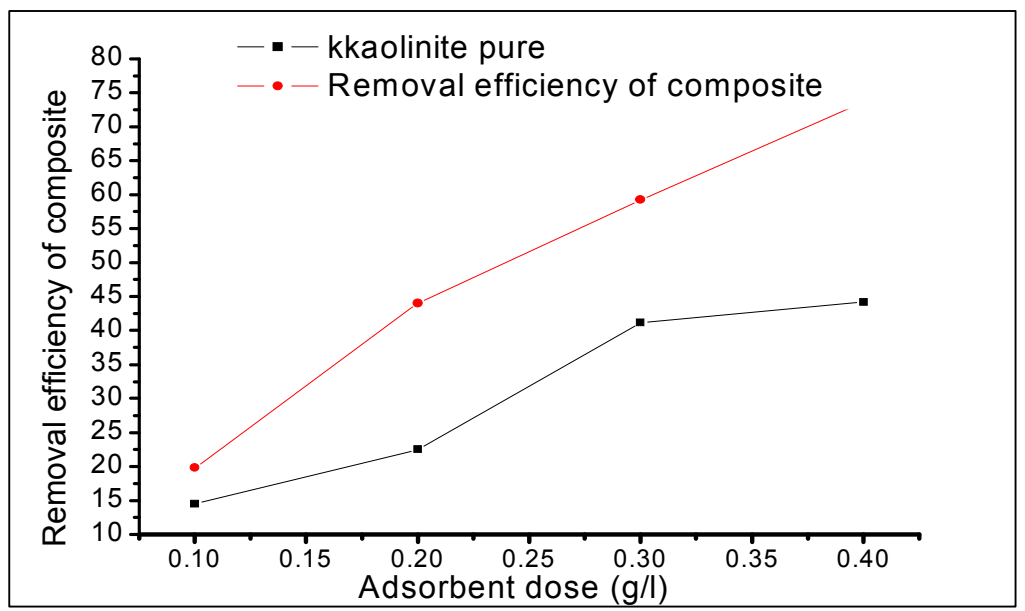

Fig. (9): Effect of adsorbent dose on the removal of $\mathrm{Cu}$ (II) percentage using kaolinite and PANAA/kaolinite composite.

The effect of $\mathrm{pH}$ on the removal of metal ions.

The $\mathrm{pH}$ of solutions was varied from 3 to 12 by the addition of $0.1 \mathrm{M}$ nitric acid and/or $0.1 \mathrm{M}$ sodium hydroxide. It was found that copper with kaolinite and its composite have almost the same trend of sorption in the $\mathrm{pH}$ range 3 to 12 . There was an observed, increase in adsorption as $\mathrm{pH}$ of metal ion solution increased. But the optimal $\mathrm{pH}$ for Copper was 5 with the pure clay and 6.5 with the modified clay. The effect of $\mathrm{pH}$ on the adsorption of $\mathrm{Cu}$ (II) by kaolinite and PANAA/kaolinite composite is shown in Figure (10). At $\mathrm{pH}$ higher than 6.5 metals were precipitated due to formation of hydroxides. At low $\mathrm{pH}$ there is low adsorption, this may be attributed to the surface of the composite containing a large number of active sites. Consequently, it may become positively charged at low $\mathrm{pH}$, leading to increase the competition between $\mathrm{H}^{+}$and the metal ions for available adsorption sites. However, as $\mathrm{pH}$ increases, this competition decreases as these surface active sites become more negatively charged, which enhances the adsorption of the positively charged metal ions through electrostatic force of attraction (Stafstrom et al., 1987). In this study, the $\mathrm{pH}[5,6.5]$ for the removal of $\mathrm{Cu}$ (II) was determined as the optimum $\mathrm{pH}$ in removal of copper from aqueous solution by clay and kaolinite clay composite respectively.

\section{The effect of contact time on the removal of metal ions}

The adsorption of metal ions on the modified PANAA/kaolinite composite can be described as a function of the contact time as shown in Figure (11). The adsorbent loading was kept at a constant value of
$0.4 \mathrm{~g}$ and a contact time from 0 to $120 \mathrm{~min}$ was employed. The majority of metal ions in adsorption equilibrium were achieved between 10 and $25 \mathrm{~min}$ for all studied ions. Adsorption first followed a linear rising in which instantaneous extremely fast uptake takes place, and then a stationary state was observed. As shown in Figures (11) the removal of metal ions was attained in the first $25 \mathrm{~min}$ for $\mathrm{Cu}$ ions and the concentration became almost constant after $30 \mathrm{~min}$. The fast initial uptake was due to the accumulation of metal ions on the surface of kaolinite and PANAA/kaolinite composite. It was concluded that 20 min was sufficient for sorption to attain equilibrium. This result revealed that adsorption of $\mathrm{Cu}$ (II) is fast and the equilibrium was achieved by 25 min of contact time. Taking into account these results, a contact time of 25 min was chosen for further experiments.

\section{CONCLUSION}

Thermal study of kaolinite and PolyanilinAnthranic acid/kaolinite composite showed that the composite have more thermal stability than the pure kaolinite. (PANAA)/kaolinite composite was effective, for which the removal reached around $70 \%$ of copper cations. Adsorption of studied heavy metals was slightly acidic $\mathrm{pH}$-dependent and the results showed that the optimum $\mathrm{pH}$ for the removal was found to be 6.5 . The optimum time to remove the high amount of the heavy metals is $20 \mathrm{~min}$ then by time the removal graph showed a stationary line. Finally from the above we can conclude that (PANAA/KC) composite can be used as effective adsorbent for the copper in the industrial wastewater and it is more effective than the pure clay. 


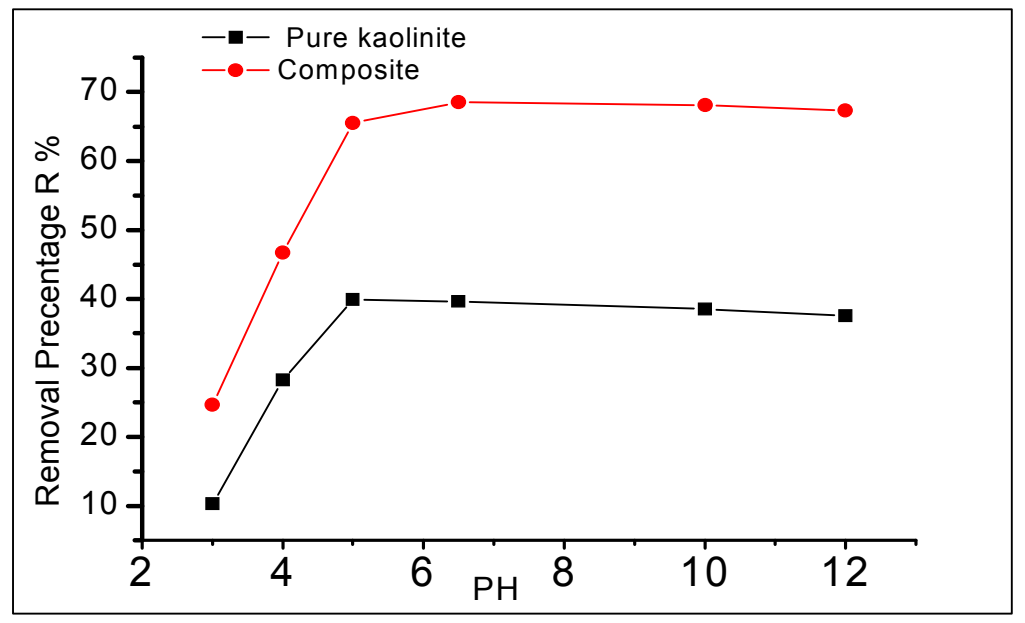

Fig. (10): Effect of $\mathrm{pH}$ on the removal of $\mathrm{Cu}$ (II) percentage using Kaolinite clay and PANAA/kaolinite composite, adsorbent dose $=0.4 \mathrm{~g} / \mathrm{L}$

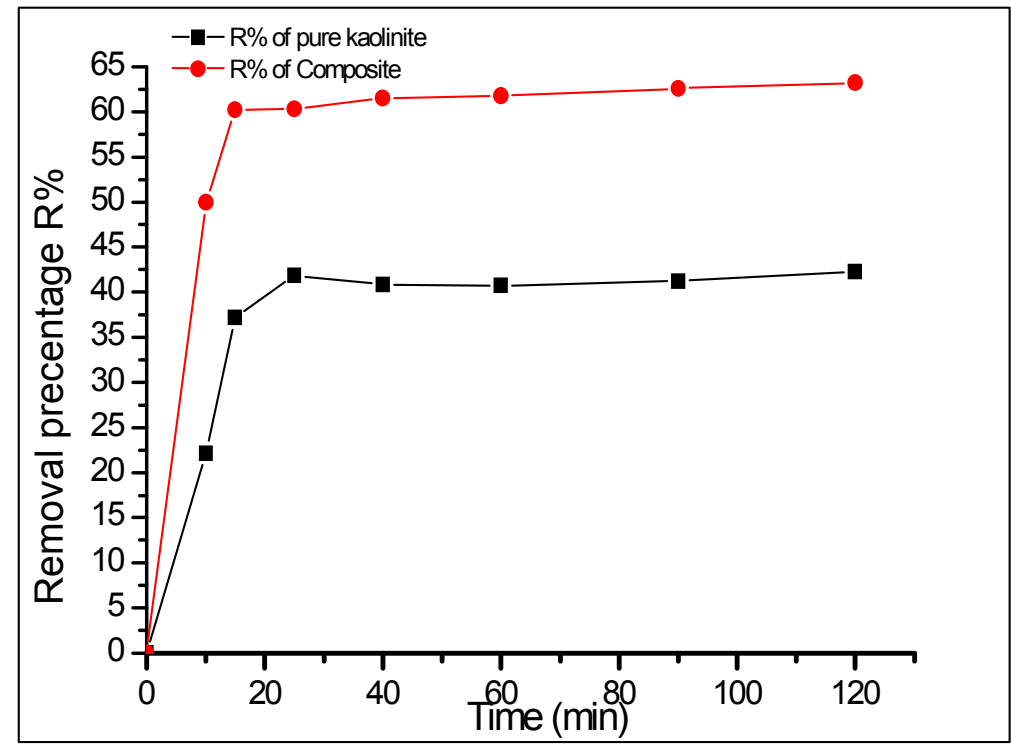

Fig. (11): Effect of Time on the removal of $\mathrm{Cu}$ (II) percentage using Kaolinite clay and PANAA/kaolinite composite, adsorbent dose $=0.4 \mathrm{~g} / \mathrm{L}$ and $\mathrm{pH} 6$

\section{REFERENCES}

Arthur, W.R. and C.B.M. Gino (1993): Adsorption of $\mathrm{Cu}, \mathrm{Pb}, \mathrm{Zn}, \mathrm{Co}, \mathrm{Ni}$ and $\mathrm{Ag}$ by goethite and hematite, a control on metal mobilization from red beds into stratiform copper deposits. Econ. Geol., 88: 1226-1236.

Backes, C.A., R.G. Mclaren, A.W. Rate and R.S. Swift (1995): Kinetics of cadmium and cobalt desorption from iron and manganese oxides. Soil Sci. Soc. Am. J., 59(3): 778-85.

Baumgarten, E. and U Kirchhausen-Dısing (1997): Sorption of metal ions on alumina. J. Colloid. Interf.. Sci., 194(1): 1-9.

Bhadra, S. and D. Khastgir (2007): In situ preparation of polyaniline coated fumed and precipitated silica fillers and their composites with nitrile rubber (Investigation on structure-property relationship). Eur. Polym. J., 43: 4332-4343.
Brian, KS and S. Garrison (1998): Effect of landfill leachate organic acids on trace metal adsorption by kaolinite. Environ. Sci. Technol., 32(10): 1404-1408.

Challier, T. and R.C.T. Slade (1994): Nanocomposite material polyanilineintercalated layered double hydroxides. J. Mat. Chem., 4: 367-371.

Epstein, A.J., J.M. Ginder; F. Zuo, W.R. Bigelow, W.S. Woo, D.B. Tanner, A.F. Ritcher, W.S. Huang and A.G. MacDiarmid (1987): Insulator-tometal transition in polyaniline. Synth. Met., 18: 303-309.

González Pradas, E., M. Villafranca Sánchez, F. Cantón Cruz, M. Socías Viciana and M. Fernández Pérez (1994): Adsorption of cadmium and zinc from aqueous solution on natural and activated bentonite. J. Chem. Technol. Biotechnol., 59(3): 289-295. 
Jinho, Jung, Cho Young-Hwan and Hahn Pilsoo (1998): Comparative Study of $\mathrm{Cu} 2+$ Adsorption on Goethite, Hematite and Kaolinite: Mechanistic Modeling Approach. Bull. Korean Chem. Soc., 19(3): 324-327.

Rajendra, P., D. Gowrisankar and L.M. Shukla (1997). Adsorption and desorption of zinc in soils. Agrochimica, 41(6): 241-246.

Saikia, B.J. and G. Parthasarathy (2010): Fourier transform infrared spectroscopic characterization of kaolinite from Assam and Meghalaya, Northeastern India. J. Mod. Phys., 1: 206-210.

Shackelette, L.W., J.F. Wolf, S. Gould and R.H. Baughman (1988): Structure and properties of polyaniline as modeled by single-crystall oligomers. J. Chem. Phys., 88: 3955-3961.
Shukla, L.M. (2000): Sorption of zinc and cadmium on soil clays. Agrochimica, 44(3-4):101-106.

Soon-Yong Jeong and Lee Jung-Min (1998): Removal of heavy metal ions from aqueous solutions by adsorption on magadiite. Bull. Korean Chem. Soc., 19(2): 218-222.

Stafstrom, S., J.L. Bredas, A.J. Epstein, H.S. Woo, D.B. Tanner, W.S. Huang, and A.G. MacDiarmid (1987). Polaron lattice in highly conducting polyaniline: Theoretical and optical studies. Phys. Rev. Lett., 59: 1464-1467.

Volzone, C. and EL Tavani (1996): Cr (III) Adsorption on kaolinite from and industrial effluent. Proceedings of the International Conferance on Clean Technologies for Mining Industry, 3(01): 121-128. 